\title{
O POETRY SLAM NO ENSINO DE LÍNGUA ESPANHOLA: UMA PROPOSTA PARA O LETRAMENTO LITERÁRIO CRÍTICO
}

\author{
POETRY SLAM IN SPANISH LANGUAGE TEACHING: \\ A PROPOSAL FOR CRITICAL LITERARY LITERACY
}

Fabiana Oliveira de Souza*

\begin{abstract}
RESUMO
O poetry slam é um gênero artístico-literário que surgiu em 1986, nos Estados Unidos, e que tem conquistado inúmeros adeptos no Brasil, tendo chegado ao país em 2008. A partir de 2015, o Slam da Guilhermina, segundo coletivo brasileiro a ser criado, passa a organizar o Slam Interescolar SP, campeonato de poesia falada que já reuniu centenas de escolas públicas da cidade de São Paulo ao longo destes anos, contando com a participação de estudantes do Ensino Fundamental e Médio. Assistindo a algumas dessas competições, é possível observar sua capacidade de mobilização da comunidade escolar, que se reúne em torno de um expressivo número de alunos que se dispõem a produzir e compartilhar suas poesias, por meio das quais problematizam temas diversos, o que torna o slam um forte aliado no processo de formação cidadã desses sujeitos. Com base nesses dados, este trabalho apresenta uma proposta de inserção, nas aulas de Língua Espanhola, do poetry slam realizado em países hispanofalantes, reproduzindo a experiência do Slam Interescolar SP, com o objetivo de desenvolver um letramento literário crítico (COSSON, 2009; STREET, 2014; DUBOC, 2014; MARINS-COSTA, 2016) e um ensino ancorado nas perspectivas intercultural (PARAQUETT, 2011, 2012; MATOS, 2018) e decolonial (QUIJANO, 2000; GROSFOGUEL, 2008; MATOS; SILVA JÚNIOR, 2019), incentivando um maior engajamento discente nas práticas de leitura. Como se trata ainda de uma proposta, espera-se que ela seja adaptável a diversas instituições de ensino que ofereçam essa disciplina, respeitando-se suas respectivas peculiaridades.
\end{abstract}

Palavras-chave: poetry slam; ensino de espanhol; letramento literário; interculturalidade; decolonialidade.

\section{ABSTRACT}

Poetry slam is an artistic and literary genre created in 1986, in the United States, which has been gaining supporters since its first play in Brazil, in 2008. As of 2015, Slam da Guilhermina, the second Brazilian group ever created, will now organize the Slam Interescolar SP, a spoken word poetry competition that has, over those years, already gathered hundreds of public schools from the City of São Paulo, with the participation of Elementary and High School students. By watching a few of those competitions, it is possible to observe its ability to mobilize the school community, which gathers around an expressive number of students willing to produce and share their poetry, through which they problematize a diverse range of issues, which makes the slam a strong ally in the process of raising civic awareness in those individuals. Based on such data, this paper presents a proposal for insertion of poetry slam from Spanish-speaking countries into Spanish Language classes, in order to develop a critical literary literacy (COSSON, 2009; STREET, 2014; DUBOC, 2014; MARINS-COSTA, 2016) and a teaching process anchored on intercultural (PARAQUETT, 2011, 2012; MATOS, 2018) and decolonial perspectives (QUIJANO, 2000; GROSFOGUEL, 2008; MATOS; SILVA JÚNIOR, 2019), encouraging higher engagement of students in reading practices. Since it is still a proposal, it is expected to be adaptable to different educational institutions offering that subject, respecting their respective particularities.

Keywords: poetry slam; Spanish teaching; literary literacy; interculturality; decoloniality.

\section{INTRODUÇÃO}

É preciso ter consciência que nenhuma proposta de ensino de línguas é política e culturalmente neutra.

Hilário I. Bohn, 2000, p. 130.

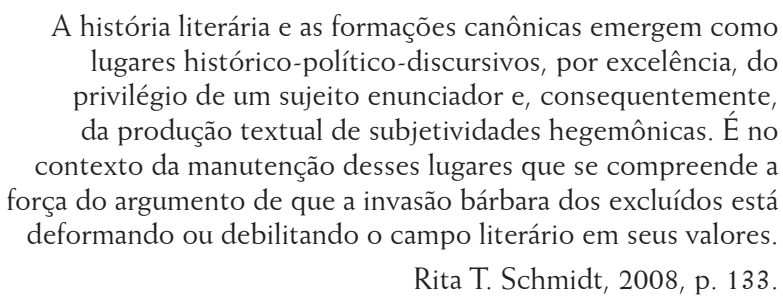

\footnotetext{
* Doutoranda em Letras Neolatinas pela Universidade Federal do Rio de Janeiro (UFRJ), Rio de Janeiro, RJ, Brasil. fabiana.oliveira.de.souza@ letras.ufri.br

Orcid: https://orcid.org/0000-0002-6045-0092

Agradeço ao CNPq pela bolsa de doutorado que possibilitou esta pesquisa (CNPq 140975/2020-9). Agradeço também ao Ary Pimentel, à Adriana Gonçalves da Silva, ao Marcel Amorim e ao Antonio Ferreira da Silva Júnior pelas valiosas discussões.
} 
O objetivo central deste artigo é propor a inserção, nas aulas de Língua Espanhola, da poesia-slam escrita e performada neste idioma, a fim de propiciar o que seria a sua culminância: a criação de um Slam Escolar e Interescolar produzido em espanhol, a ser realizado por instituições brasileiras onde a disciplina seja ofertada. Trata-se de uma atividade educacional voltada a um ensino que auxilie no desenvolvimento de um letramento literário crítico e que se guie pelas perspectivas intercultural e decolonial, configurando-se como "um trabalho que se ocupe em refletir e diminuir desigualdades sociais" (CADILHE; LEROY, 2020, p. 250), pelos aspectos que caracterizam a corrente artístico-literária do poetry slam e por outras razões que serão apresentadas mais detidamente ao longo do texto.

Ao pensarmos na relação entre a Linguística Aplicada (LA) e as investigações dessa área preocupadas com o ensino de espanhol como língua estrangeira no Brasil, percebemos que o que se propõe aqui se alinha à LA crítica (PARAQUETT, 2012), a qual nos orienta a um tipo de estudo que valoriza as reais histórias de sujeitos marginalizados e silenciados, levando-nos a um olhar suleado e decolonial ${ }^{1}$ para tais vivências.

A proposta se pautará nas experiências de realização de slams no contexto escolar, com foco no Slam Interescolar $\mathrm{SP}_{1}^{2}$ competição de slam que acontece na cidade de São Paulo desde 2015 e que está voltada para o Ensino Fundamental (segundo segmento) e para o Ensino Médio. Tais experiências foram resgatadas a partir de vídeos e relatos (orais e escritos) que compõem nosso corpus e serão analisadas com o intuito de oferecer subsídios para justificar a motivação para o que idealizamos aqui, fortalecendo a ideia de que é possível desenvolver um slam intra e interescolar em língua espanhola, estendendo-se o que já se faz em língua portuguesa no Brasil.

Para tratar desta proposição, dividiu-se o artigo em quatro partes: a primeira se destina à discussão sobre letramentos (literário, crítico, de reexistência); a segunda, às relações entre interculturalidade e decolonialidade em um ensino de língua espanhola suleado; a terceira, à análise do corpus, a fim de refletir sobre a possibilidade de concretização da atividade pedagógica sugerida, além de demonstrar sua relevância; e a última, à descrição das etapas recomendadas para sua execução.

\section{O LETRAMENTO LITERÁRIO CRÍTICO}

Como afirma Duboc (2014, p. 210), no ensino-aprendizagem de uma língua estrangeira, estudam-se não apenas os aspectos linguísticos, mas também os "identitários, culturais, sociais, ideológicos", daí a importância de um ensino de línguas preocupado com a formação crítica dos estudantes. O letramento crítico, por meio do qual podemos incluir "em nossas aulas a heterogeneidade, a subjetividade, a contextualização e a problematização" (DUBOC, 2014, p. 217), é o que permite uma educação capaz de abrir brechas em um modelo didático tradicional, que se idealiza como homogêneo e estável.

Assim como toda produção discursiva, as práticas de letramentos são situadas social e historicamente e, portanto, podem ajudar a construir ou a desconstruir certas identidades e relações de poder entre os sujeitos, que estão em disputa constante pelo direito à legitimidade de seus saberes e suas formas de vida. Como aponta Souza (2011), a esfera escolar não costuma privilegiar os letramentos exocanônicos, isto é, que não estão inseridos no cânone, e que são praticados por grupos sociais que deveriam ser vistos "não pela ausência, mas pela presença de conhecimentos não valorizados socialmente" (SOUZA, 2011, p. 35).

Ao tratarmos de letramento literário, tampouco fugimos do tradicional, pois as obras e os gêneros literários que geralmente são selecionados, ainda hoje, são aqueles que nossos professores nos apresentaram e que foram também os que eles estudaram em sua educação básica. Soma-se a isso o fato de que, como argumenta Cosson (2009), o ensino de literatura na escola costuma se reduzir à história literária, tratando de correntes e suas características, e muitas obras são trabalhadas apenas de modo superficial, como um pretexto para aprender um conteúdo linguístico. Segundo Marins-Costa (2020), é comum, ainda, que se ignore o fato de que cada texto é lido de uma forma diferente e o objetivo de tal leitura acaba sendo o de encontrar determinadas informações explícitas.

1. Optou-se por decolonial em vez de descolonial porque, conforme explica Walsh (2013), o des-colonial pode ser entendido como uma possibilidade de desfazer o que foi o momento colonial e de apagar suas marcas; o de-colonial, por sua vez, denota uma atitude de luta e de resistência ao que se manteve como herança desse momento. Portanto, é possível viver nesse universo dominado pelas colonialidades (do poder, do ser, do saber etc.) e concomitantemente questioná-lo e agir contra ele.

2. Concentramo-nos aqui no Slam Interescolar da cidade de São Paulo (capital do estado brasileiro homônimo), que foi o primeiro do país, mas essa modalidade de slam já está presente em outros estados, como veremos posteriormente. 
O que resulta de tudo isso é que as obras literárias, quando estudadas, não são exploradas levando-se em consideração as múltiplas possibilidades de fruição de cada texto, cuja leitura deve ser ensinada como se faz com qualquer outro, como afirma Cosson (2009, p. 23) ao defender que

[é] fundamental que se coloque como centro das práticas literárias na escola a leitura efetiva dos textos [...]. Essa leitura também não pode ser feita de forma assistemática e em nome de um prazer absoluto de ler. Ao contrário, é fundamental que seja organizada segundo os objetivos da formação do aluno, compreendendo que [...] o letramento literário é uma prática social e, como tal, responsabilidade da escola.

É esse ensino sistematizado e planejado de literatura que pode oferecer ao estudante não apenas meros dados sobre a disciplina, mas "uma experiência de leitura a ser compartilhada" (COSSON, 2009, p. 23), que é o que nos interessa para o projeto que propomos neste artigo, uma vez que a poesia do slam é feita para ser lida em voz alta e para interpelar o outro, em performances que dependem do componente receptor - os interlocutores - para coconstruir seus sentidos (ZUMTHOR, 2014). Além disso, uma vez que o próprio ato de ler já significa "envolver-se em uma prática social, [...] se as condições sociais, políticas, culturais e históricas relacionadas tanto com a produção quanto com a leitura do texto não são consideradas, torna-se inviável ler criticamente o texto" (MARINS-COSTA, 2016, p. 38), por isso é essencial ter essas questões em mente.

O letramento por si só não indica automaticamente que haja criticidade nas relações entre leitor/ouvinte e os textos escritos e orais. A este respeito, Street (2014) estabelece distinções entre um enfoque autônomo ${ }^{3}$ e um enfoque ideológico do letramento: no primeiro, os textos e os sujeitos são vistos de forma homogênea, independentemente do contexto social que os abarca; trata-se de um modelo que privilegia - quando não se limita a - o trabalho com gêneros discursivos e práticas sociais canônicas, que se repetem e monopolizam as aulas a cada ano; enquanto no segundo, reconhece-se a variedade de práticas culturais envolvendo a leitura e a escrita, evidenciando-se que os letramentos estão inextricavelmente associados às relações identitárias, culturais e de poder. Este último é o modelo que se alinha ao proposto neste artigo, pois é o que nos permite considerar o poetry slam - estando ao lado de gêneros textuais e discursivos já consagrados - como prática social tão válida quanto qualquer outra para a formação de um indivíduo e que, por essa razão, pode ser um grande aliado para o letramento literário crítico.

A sala de aula e todo o espaço escolar devem ser um lugar de interação onde os estudantes se sintam à vontade para construir e reconstruir sentidos sobre quem eles são e sobre quem são aqueles com quem estabelecem essas trocas. Para isso, o ambiente deve ser favorável à circulação inclusive dos textos menos formais, orais e escritos, com os quais eles provavelmente estarão habituados, e não apenas os gêneros tradicionais e os autores clássicos, muitas vezes estudados sem que haja qualquer relação com a sua realidade para fora dos muros da escola.

Ademais, por se tratar de uma prática de letramento que incentiva tanto a escrita quanto a oralidade - já que os poemas são escritos para, posteriormente, serem oralizados -, o poetry slam é um exemplo de que literatura se refere tanto ao texto escrito quanto ao não-escrito, já que há múltiplas formas de manifestação literária (FINNEGAN, 2005). A própria Base Nacional Comum Curricular (BNCC) do Ensino Médio prevê que se trabalhe também com gêneros orais, na fruição e na produção, inclusive indicando a participação em eventos como os slams como uma das habilidades do campo artístico-literário, vinculado à área de Língua Portuguesa no documento (BRASIL, 2017, p. 515).

Outro aspecto a ser considerado ao trabalharmos com o poema-slam se refere ao caráter estético desse gênero literário, pois estamos diante de um texto feito para ser falado/lido em performances que são tão efêmeras (PHELAN, 2011) que somente conseguimos perpetuar os resíduos do que elas foram se as registrarmos em vídeos. Tais apresentações, que exploram a potência dos corpos-vozes dos poetas, têm como elemento sine qua non a recepção (ZUMTHOR, 2014), o que exige que eles estejam atentos ao outro, isto é, a quem chega sua palavra falada, já que é na interação com os interlocutores de uma performance que seus significados se constroem.

Pensando nessas outras formas de letramento, Souza (2011) aborda as práticas de jovens do movimento cultural hip-hop que, a partir dele, questionam e reinventam sua escola e valorizam diversas práticas linguísticas para além das legitimadas, descobrindo e (re)significando os "letramentos da vida", pelos quais é possível reexistir. Segundo a autora, os ativistas do bip-hop atuam como "agentes de letramentos" (SOUZA, 2011, p. 18) e criam um espaço não

3. Cabe destacar que os letramentos ditos autônomos também possuem um caráter ideológico, já que estão a serviço de determinados discursos conservadores. Portanto, essa diferenciação entre autônomo e ideológico a que nos referimos nos serve, principalmente, para enfatizar a atitude que predomina em cada um. 
apenas de fala, de escrita, de performance e de visibilidade, mas também de escuta atenta, de valorização mútua de suas produções e inquietações levadas a público. Pelas semelhanças com esse movimento, particularmente em relação ao rap, essas definições de Souza (2011) podem ser aplicadas ao poetry slam, em que vemos igualmente o protagonismo dos jovens. ${ }^{4} \mathrm{O}$ rap, define a autora, é a poesia cantada pelo poeta (na figura do $\mathrm{MC}$ ) que dissemina "as narrativas do cotidiano ao mostrar como vivem as pessoas, quais são seus sonhos, necessidades e formas de enfrentar os problemas" (SOUZA, 2011, p. 16) e as múltiplas desigualdades. Com isso, podemos considerar esses letramentos como modos de reexistência, uma vez que os sujeitos neles envolvidos se reinventam e (re)(co)constroem suas identidades e funções sociais nos diversos ambientes pelos quais circulam.

É importante resgatar aqui esses apontamentos porque, como acabamos de afirmar, estão totalmente alinhados com o que se observa nas batalhas do poetry slam, que também são formas de "letramentos literários de reexistência", como considera Neves (2017). A inserção dessas práticas na sala de aula de línguas mostra uma atitude docente preocupada com um ensino que privilegie modos historicamente marginalizados de ser, de relacionar-se, de pensar e de estar no mundo, questionando as colonialidades que nos acompanharam em nossa formação e que ainda têm muita força em quase todos os espaços pelos quais passamos.

Além disso, foge-se do óbvio e da mera reprodução dos tipos de textos que faremos circular em nossas aulas. Como aponta Schmidt (2008, p. 127), tem ocorrido um deslocamento da "definição de literatura como arte ou objeto estético, para a noção de literatura como produção estético-escritural", o que nos permite questionar um dos principais produtos da formação dos cânones literários: a supervalorização do que se entende como "alta cultura" e a consequente diminuição do valor de uma cultura considerada menor, na qual se enquadraria o circuito dos slams. A "revolução nos estudos literários contemporâneos", de que também nos fala Schmidt (2008, p. 127), diz respeito a uma profunda revisão dos critérios historicamente aceitos para a definição de um texto como literário ou não, requisitos que operam exclusões e apagamentos.

Nesse deslocamento do sentido do literário, aproximando arte e cultura, é que passamos a enxergar a literatura para além de seu valor estético, admitindo que o que se produz pelos sujeitos das margens, isto é, por aqueles não incluídos no cânone até então e que vêm das classes mais empobrecidas da sociedade, também possui valor literário. Com isso, deixamos de ver com maus olhos - não sem resistências dos mais conservadores - a forte presença da dimensão ideológica e sociocultural da produção literária desses grupos, além da possibilidade de admitirmos que o pacto estabelecido entre leitor/ouvinte e autor seja o aspecto que torna um texto literário.

Sendo assim, um dos ganhos com a inserção do poetry slam nas aulas de línguas é o incentivo à leitura dessa "literatura de (re)existência", vendo-a como "uma prática artística de linguagem que permite aos sujeitos historicamente violentados e discriminados - como negros/as, pobres, homossexuais, indígenas, mulheres - a possibilidade de agência e ressignificação estético-políticas de suas identidades" (AMORIM; SILVA, 2019, p. 173), em um esforço, via literatura, de reescrita de sua própria história.

\section{A PREMÊNCIA DE UMA PERSPECTIVA INTERCULTURAL E DECOLONIAL NO ENSINO}

De acordo com Ballestrin (2013), o giro decolonial é um movimento político, teórico e epistêmico de resistência ao modo moderno/colonial de compreensão do mundo. Segundo Quijano (2000), a colonialidade do poder, que é fruto do colonialismo e que define o capitalismo colonial/moderno e eurocentrado como padrão de poder hegemônico, influencia ainda hoje a forma de representação da história e da identidade da América Latina. Trata-se de uma "identidade geocultural" (QUIJANO, 2000, p. 221) que foi criada pelos brancos para diferenciar conquistadores e conquistados, classificando-os pela ideia de raça, sempre colocando como subalternos e inferiores os não-brancos. Tal classificação, além de marginalizar esses grupos sociais e suas respectivas culturas e de reprimir seus modos de produzir conhecimento e sentidos, cumpre a função de homogeneizá-los, isto é, de apagar a rica diversidade que os constitui, fazendo com que os vejamos de uma única forma possível: inferiores e menos humanos, que só conhecem a barbárie e, portanto, precisavam ser dominados e civilizados, como problematiza Zea (2005).

Partindo do pressuposto de que essa visão sobre as culturas hispânicas persiste no imaginário do senso comum é que se compreende a premência de um ensino de língua espanhola baseado em uma perspectiva decolonial e, de

4. Ainda são poucos os estudos em que se relacionem letramento e slam (NEVES, 2017, 2021), por isso comparamos o bip-hop aos slams, segundo considerações de Souza (2011). 
modo indissociável, intercultural. Isso porque "a perspectiva intercultural no ensino de línguas pressupõe [...] uma série de ações em prol do reconhecimento da diversidade que nos constitui e do combate a atitudes de discriminação para com o outro" (MATOS, 2018, p. 21). Ao reconhecer-se essa diversidade, tornamo-nos mais abertos a conhecer outras culturas e passamos a respeitá-las enquanto formas de viver e relacionar-se tão relevantes quanto aquelas com as quais nos identificamos, deixando, assim, de ver as diferenças como exóticas ou anormais. Para Matos (2018, p. 21),

[o]s professores que atuam nas escolas precisam estar preparados para o desenvolvimento de aulas baseadas na visão educacional do ensino de línguas, e [...] aponto a perspectiva intercultural como uma necessidade para a mediação tanto em sala de aula como fora do ambiente escolar. Conforme Paraquett (2010), o prefixo inter sugere uma relação recíproca entre duas partes, como uma integração, encontro e diálogo, quando se entende a aprendizagem de uma outra língua como acesso a outra cultura.

O primeiro passo para essa educação intercultural é o reconhecimento de que as diferenças culturais entre os povos são absolutamente normais, e, por esse motivo, não devem ser vistas como um problema ou como algo extraordinário (PARAQUETT, 2011), a fim de minimizar as tensões inevitáveis - por conta da série de préconceitos que todos temos - quando o assunto é o encontro entre distintas culturas. Por isso é tão importante formar professores potencialmente interculturais em sua prática docente, como defende Paraquett (2011). Para a autora, a interculturalidade é uma postura de vida, ideológica, política, mas que precisa ser transformada em ação para acontecer realmente. Além disso, não deve se tornar uma comparação entre os modos de viver de uma cultura e de outra, mas sim uma forma de agir em prol do direito de todas as pessoas, contra os preconceitos e as hegemonias baseadas nas ideias de raça, gênero, sexualidade, nacionalidade e regionalidade. Atuar segundo a interculturalidade, ainda segundo Paraquett (2011), é entender onde estão esses conflitos e fragilidades e buscar ações que desfaçam esses preconceitos todos.

No campo das pesquisas em LA, isso explica também a importância de que a tomemos como "espaço de desaprendizagem" (FABRÍCIO, 2006), pautada nas perspectivas intercultural e decolonial para sulear nosso olhar para o ensino de línguas (mais especificamente a língua espanhola, foco deste artigo). Essa noção de desaprendizagem nos remete a uma "revisão de suas bases epistemológicas", a uma "reconstrução de conhecimentos consagrados", para a construção de uma LA com um "novo horizonte de trabalho, comprometido política e eticamente com a transformação social" (FABRíCIO, 2006, p. 48 e 49). Isso não significa uma ruptura total e aleatória com tudo o que se fez antes. Em vez disso,

[t]al posição, sem desprezar conhecimentos consagrados, nos força a contínuos deslocamentos, movimentando o ângulo de observação do centro [...] para as franjas do sistema globalizado, para as organizações invisíveis, para as periferias, para as formas de ser consideradas subalternas ou inferiores (quanto à sexualidade, à raça, à classe social etc.) (FABRÍCIO, 2006, p. 51).

Para este trabalho em particular, interessam-nos as contribuições dessa LA às investigações da área de ensino de língua espanhola no contexto brasileiro, pois a passagem a uma LA INdisciplinar (MOITA LOPES, 2006) gera engajamento e atenção às mudanças sociais e a coloca em constante diálogo com pesquisadores de diversas áreas do conhecimento que estejam fora do eixo Europa-Estados Unidos (KLEIMAN, 2013). Com isso, a LA abre-se a outros modos do fazer científico e passa a valorizar as experiências do Sul, não necessariamente o geográfico, mas "um Sul epistêmico que corresponde às realidades e aos sujeitos socialmente marginalizados" (MATOS, SILVA JÚNIOR, 2019, p. 103).

Oferecer um ensino de língua espanhola sob a perspectiva desse suleamento e da decolonialidade requer, em primeiro lugar, que o professor reflita sobre a sua prática a fim de observar se aquilo que ele propõe em sala de aula não reproduz uma visão hegemônica sobre diferentes povos e culturas, contribuindo para reforçar estereótipos e estigmas associados a determinados grupos sociais. Uma postura decolonial nos levaria a revozear e valorizar as vozes silenciadas e invisibilizadas do Sul geográfico, ideológico e simbólico, em busca de uma justiça no âmbito da produção de conhecimento, memória e história ao ouvir essas narrativas. No mesmo sentido, o trabalho com a interculturalidade corresponderia a um ensino em que a diversidade cultural, linguística, racial e social fizessem parte das aulas não como meros temas ou curiosidades do mundo hispânico (no caso do ensino de espanhol), mas como aquilo que caracteriza sujeitos e grupos (MATOS, 2018) que, pela língua espanhola, se comunicam, pensam e intervêm no seu entorno.

Considerando que "por meio da linguagem são tanto (re)afirmadas como negociadas as múltiplas identidades" (BAPTISTA, 2019, p. 123), cabe refletir também sobre nossa atitude enquanto professores de línguas, já que uma das dimensões da colonialidade do poder é a colonialidade da linguagem. Assim como as outras manifestações do 
pensamento colonial, ela pode nos levar a invisibilizar e marginalizar certos povos, suas línguas e suas culturas em detrimento de outros que tomemos - conscientemente ou não - como mais importantes e que, por isso, recebam mais destaque e valor em nossas aulas.

É contra esse tipo de postura colonial que devemos direcionar nossos esforços, pois, segundo Grosfoguel (2008, p. 126), "a colonialidade permite-nos compreender a continuidade das formas coloniais de dominação após o fim das administrações coloniais, produzidas pelas culturas coloniais e pelas estruturas do sistema-mundo capitalista moderno/colonial". Isso ainda hoje interfere nas questões de gênero, sexualidade, raça, política, classe social, subjetividades e linguagens, entre outras, por isso é tão urgente que haja uma atitude alternativa, de combate a esse pensamento.

Conforme Baptista (2019), desconstruir a colonialidade da linguagem é importante, entre outras razões, porque ela influencia a educação linguística ao reforçar as "relações de poder entre as línguas e os sujeitos subalternizados" (BAPTISTA, 2019, p. 123), e é um dos fatores que contribuem para que a escola reforce essas assimetrias e as desigualdades entre os indivíduos. Este é mais um motivo para defendermos aqui a inserção do poetry slam nas escolas, pois a linguagem do poema-slam, bem como o conteúdo veiculado por tal linguagem, surge como proposta de ruptura e contranarrativa e como meio pelo qual sujeitos do Sul e das margens literárias - já que tradicionalmente não representam o cânone - propõem uma nova dicção e erguem sua voz, tão indesejada em tantos espaços.

Em síntese, uma perspectiva intercultural e decolonial no ensino de línguas resultaria em um tipo de trabalho, no ambiente escolar, que questione e desestabilize as estruturas, ainda firmes, erguidas pela colonialidade e que têm nos levado há séculos a aceitar o poder, a cultura e o conhecimento euro-eua-centrados (WALSH, 2009) como um modelo a ser seguido, o que, na prática, significa a dominação sobre corpos e ações não hegemônicos.

\section{UM SLAM ESCOLAR E INTERESCOLAR EM ESPANHOL COMO LÍNGUA ESTRANGEIRA É POSSÍVEL}

O poetry slam é um gênero artístico-literário que surgiu em 1986 no subúrbio de Chicago, nos Estados Unidos, e que vem ganhando cada vez mais adeptos no Brasil desde seu surgimento por aqui, em 2008 (ESTRELA D'ALVA, 2011). Desde 2015, organiza-se anualmente o Slam Interescolar SP, competição de poesia que já reuniu centenas de escolas públicas ao longo destes anos, contando com a participação de estudantes do Ensino Médio e do segundo segmento do Ensino Fundamental. Trata-se do projeto intitulado "Das ruas para as escolas, das escolas para as ruas", concretizado por iniciativa do Slam da Guilhermina, coletivo que organiza slams de poesia na Zona Leste de São Paulo, em uma praça anexa a uma estação de metrô, tendo sido o segundo a ser criado no Brasil e o primeiro a ser realizado nas ruas. Como descreve Neves (2021, p. 80), "de modo geral, a proposta educacional subjacente a tais atividades do Coletivo da Guilhermina é incentivar jovens estudantes do ensino fundamental e médio a escreverem poesias para apresentá-las em voz alta, performaticamente, nos eventos escolares de slams".

Como informado ao início do texto, o intuito deste trabalho é apresentar uma proposta de inserção, nas aulas de Língua Espanhola, de poemas-slam produzidos por slammers de países hispanofalantes, para que possa auxiliar no desenvolvimento de um letramento literário crítico e um ensino pautado nas perspectivas intercultural e decolonial, incentivando um maior engajamento dos estudantes. A ideia é extrapolar o espaço da sala de aula e reproduzir a experiência do Slam Escolar e Interescolar, mas com textos escritos e oralizados em espanhol, o que poderia despertar o interesse de mais alunos por essa disciplina, que vem sendo desvalorizada e perdendo visibilidade no Brasil nos últimos anos, principalmente com o retrocesso que a BNCC representou para o ensino de língua espanhola no país, discussão que será retomada ao final.

O que se propõe neste artigo tem como base a análise do seguinte corpus: 1) dois vídeos do Slam Interescolar $\mathrm{SP}$, que registram, além de outros elementos da cena, a performance de dois alunos-poetas que venceram as edições de 2016 e 2018; 2) o relato de Emerson Alcalde $(2016$, 2021), publicado em livros do Slam da Guilhermina, sobre a experiência da primeira edição do evento, em 2015; 3) o áudio do episódio sobre poesia e educação do Podcast Podfalar, com Alcalde e dois slammers que atuaram como poetas-formadores nas escolas participantes do projeto; e 4) a entrevista de Emerson Alcalde ao Instituto Hilda Hilst (on-line) também sobre o Slam Interescolar SP.

Apesar de concentrarmos nossa análise no caso de São Paulo, hoje já existem slams interescolares em outras partes do país, tais como Bahia, Rio de Janeiro, Mato Grosso do Sul, Minas Gerais e Espírito Santo (NEVES, 2021). 
Além da análise do corpus selecionado, a ideia de expandir o que já é feito e criar-se um slam interescolar em espanhol como língua estrangeira se ancorou em um cuidadoso estudo realizado por Émery-Bruneau e Yobé (2014) sobre as diferenças entre o slam como prática social e como objeto de ensino na escola, a partir da experiência com essa atividade artístico-literária em Quebec, no Canadá, onde também há um campeonato nacional interescolar de poesia. De acordo com as autoras, no caso observado, notou-se que, na transposição didática das competições de slam que ocorrem fora do ambiente escolar, essas práticas acabaram por se resumir a objetos de estudo, diferente do que se espera com o que propomos aqui. O objetivo é que a proposta evolua e se torne um projeto permanente, e não uma atividade que ocorra uma única vez.

Da mesma forma, é fundamental que o poetry slam seja entendido nas escolas como mais que um recurso pedagógico, deixando em evidência a potência desses eventos enquanto práticas de letramento legítimas que têm atraído cada vez mais os jovens e que não deveriam ser desvalorizadas. Para isso, é importante envolver, no processo de inserção dos slams nesses espaços, sujeitos que façam parte das diversas esferas que compõem a comunidade escolar, e não apenas os docentes de Língua Espanhola e seus alunos. Ademais, uma vez que se busca reconhecer seu valor, é preciso que se mantenham, sempre que possível, as dinâmicas dos campeonatos realizados nas ruas, a fim de que essas práticas não percam sua essência e, como consequência, se descaracterizem e se tornem qualquer outra coisa, apenas para se adequarem àquilo que é aceito e legitimado.

Essa lógica tem guiado, desde o início, o Slam Interescolar SP, cuja inspiração veio de longe. O escritor e slammer Emerson Alcalde $(2016,2021)$, cofundador do Slam da Guilhermina, relata que a ideia de criar um slam entre escolas surgiu após assistir ao vivo a um campeonato de poesia falada com crianças na França, em 2014, onde ele estava para participar da Copa do Mundo de Poesia representando o Brasil. De volta ao país, ele propôs aos integrantes da Guilhermina que se reproduzisse o movimento em escolas de São Paulo (ALCALDE, 2016, 2021; NEVES, 2021). A proposta se concretizou em 2015, quando ocorreu o primeiro Slam Interescolar, inserido aos poucos nas escolas por meio de sessões de slam, palestras e diversas oficinas de poesia ministradas por poetas do próprio coletivo. Como afirma Alcalde (2016, p. 7), tais atividades tinham "o propósito de incentivar alunos e professores a fazerem seu próprio slam" e o projeto teve êxito "porque houve comprometimento dos professores, coordenadores e dos alunos [...] e o envolvimento humano foi criado, provando que é possível aproximar a literatura dos jovens" (ALCALDE, 2016, p. 10), uma preocupação bastante comum atualmente.

Uma estratégia para impulsionar esses jovens a produzir textos poéticos é promover uma discussão com eles em que se problematize a ideia de poesia como algo solene e tão alheio a ponto de que, para muitos deles, pareça impossível que também sejam capazes de fazer. Muitas vezes, o modo convencional de se trabalhar com esse gênero literário, mais preocupado em estudar sua estrutura e ensinar teoria da literatura, tipos de versos e estrofes ou a história das correntes literárias, pode ser um fator responsável por gerar no aluno essa sensação de distância em relação à poesia, vendo-a como difícil e entediante. O ideal é mostrar que há várias manifestações do fazer poético, cada uma com suas características e seu valor, e, naturalmente, algumas pessoas terão mais afinidade como uma ou outra. O próprio slam tem sido uma ferramenta de motivação para que os estudantes se interessem pela poesia, de acordo com o relato supracitado de Emerson Alcalde. Por esse motivo, vemos um potencial nessas competições para estimular os estudantes a se tornarem mais participativos nas aulas de Língua Espanhola ao verem slammers performando nesse idioma, da mesma maneira como se tem feito a partir dos slams brasileiros.

Expandir a visão dos alunos sobre o que é poesia pode fazer com que eles percebam que, além de leitores, também podem ser poetas, tornando-se sujeitos mais ativos no processo de construção desse gênero literário que, com isso, sai de um lugar inacessível para ir ao encontro dos aprendizes. É importante que eles saibam que um poeta não é um indivíduo que faz parte apenas de épocas remotas, mas também de seu tempo, podendo encontrá-lo pessoalmente em um evento literário ou mesmo em sua escola para conversarem sobre suas obras.

Em conversa sobre poesia e educação no Podcast Podfalar, Alcalde (2020) afirmou que o slam nas escolas tem sido uma forma de dar autonomia para que os alunos se expressem e revelem o que têm sentido, relatando suas vivências. É também um modo de aproximar corpo docente e discente porque foi possível mapear, pelos temas que predominam em seus poemas, quais questões são mais relevantes para eles, isto é, o que os incomoda. Dessa forma, o Slam Interescolar acaba atuando como uma prática social de grande valia no processo de letramento crítico, visto que serve como uma ponte para que os estudantes se tornem sujeitos questionadores, que problematizam inclusive a estrutura de seu próprio colégio. 
Por conta dessa ação de estímulo ao senso crítico, Alcalde comentou, em entrevista que concedeu a Renato Musa e Amanda Panciera, do Instituto Hilda Hilst (EDUCAÇÃO, 2020), que nem todas as escolas recebem bem a ideia do poetry slam e que, por essa razão, algumas não quiseram participar nos outros anos. Apesar disso, o número de instituições inscritas só vem aumentando: passaram de quatro, em 2015, a mais de cem, em 2020. Essa não é a única mudança que se destaca, pois, como relatou Alcalde nesta mesma entrevista, percebeu-se que os estudantes se sentiram com mais liberdade para abordar em seus poemas temáticas que geralmente são encaradas como tabu nas escolas, como o assédio sexual, por exemplo.

A potência desses discentes, bem como do próprio evento em si, pode ser observada nos variados vídeos que divulgam algumas edições do Slam Interescolar SP. ${ }^{5}$ Um deles é o de Isaac Quaresma, representante do Ensino Fundamental e vencedor do campeonato de 2016. Na ocasião, Isaac é ovacionado pelos colegas após sua performance e ao ser anunciado como campeão, em um centro cultural lotado. Podemos ver, ao final do vídeo, uma mesa com os prêmios que os estudantes recebem: medalhas, troféus, certificados e muitos livros de poesia. Outro registro é o da estudante Evelen Giovanna, do Ensino Médio, campeã da edição de 2018. Assim como Isaac, Evelen aborda o tema do machismo e do assédio contra a mulher, acompanhada pelos olhos e ouvidos atentos de uma plateia envolvida e que vibra durante e ao final de sua apresentação. Um terceiro caso ocorreu na live de lançamento do livro Das Ruas para as Escolas, das Escolas para as Ruas - Slam Interescolar SP, em junho de 2021, quando pudemos ouvir o relato emocionado e emocionante de Luara Maysa, que, aos 13 anos, foi campeã do primeiro Slam Interescolar SP. A estudante lembra que foi por meio da competição que passou a expressar melhor sua criatividade e descobriu que podia escrever poesia e ser compreendida através dela. ${ }^{6}$ Esses exemplos são apenas alguns dentre tantos que poderíamos citar para tratar do alcance do slam por onde tem passado e para servir-nos de ponto de partida para planejarmos sua versão em língua espanhola.

Como nos adianta uma das epígrafes deste artigo, o ensino de línguas estrangeiras, bem como a própria educação, não pode ser neutro, pois é preciso que ele incentive os estudantes - mas, antes, os professores - a "problematizar as relações de poder constituídas no discurso dominante" (MATOS, 2018, p. 23). Isso é uma das bases da poesia do slam, por isso nos parece um gênero profícuo e necessário para uma educação que se oriente por esse raciocínio. Como indagam Cadilhe e Leroy (2020, p. 265), "nessa miríade de reflexões, que textos podem ser selecionados para compor projetos de letramentos decoloniais [...] nas salas de aula, colocando na cena do debate as injustiças e desigualdades sociais", além das múltiplas formas de discriminação?

Além dos vídeos recém comentados, com o intuito primeiro de apresentar o slam aos alunos, dois poemas-slam ${ }^{7}$ que já se indicariam para esse trabalho são "Gorda", de Checha Kadener, vencedora do Campeonato Nacional do Slam Argentino de Poesía Oral de 2020, e "Silencio", do trio Poesía Estéreo (extinto), apresentado em uma das primeiras edições do slam argentino de 2011, mesmo ano de seu surgimento por lá. ${ }^{8}$ No poema de Checha, encontramos uma crítica contundente à gordofobia e à imposição de um modelo estético sob a justificativa de cuidado com a saúde, quando o real motivo seria a aversão a um corpo fora dos padrões, como se ouve na performance, em especial no fragmento: "Soy gorda, eso salta a la vista [...] pero no logro sentirme marginada, a pesar de los patrones culturales, a pesar del "deberías adelgazar por tu salud'" . 9 Já no texto de Poesía Estéreo, composto por Sol Fantín, Sagrado Sebakis (criadores do slam em seu país) e Diego Arbit, nota-se uma definição do slam como algo que rompe com o modelo tradicional de poesia e do que é ser poeta, descrevendo essa corrente como uma prática aberta a todos e onde não há espaço para exaltação daqueles que tenham mais prestígio social que outros, por conta de publicações ou formação acadêmica, como percebemos em versos como "abandonen, lentamente, sus viejas nociones sobre poesía" e "acá a nadie le importan tus amigos periodistas ni tus sesenta libros editados y traducidos al sueco". ${ }^{10}$

5. Os vídeos podem ser encontrados na página oficial da competição no Facebook e/ou no canal do Slam da Guilhermina no YouTube. Os links para os que mencionamos aqui encontram-se ao final do texto, nas referências.

6. O registro da live está disponível em: https://www.youtube.com/watch?v=N1IhleAHZww. Acesso em: 13 jun. 2021.

7. Há, pelo menos, um vídeo de Checha Kadener e um do Poesía Estéreo apresentando esses textos, que estão disponíveis, respectivamente, em: https://www.youtube.com/watch?v=V3GjQANCLX0 e https://www.youtube.com/watch?v=oV8cmemgozQ. Acesso em: 14 mar. 2021.

8. De acordo com informações presentes no antigo blog do Slam Argentino de Poesía Oral: http://slamargentina.blogspot.com/. Outros dados também podem ser encontrados em uma reportagem do jornal Clarín (LA POESíA, 2012).

9. "Sou gorda, isso está na cara [...] mas não consigo me sentir marginalizada, apesar dos padrões culturais, apesar do 'você deveria emagrecer pela sua saúde"" (tradução nossa).

10. "Abandonem, lentamente, suas velhas noções sobre poesia" e "aqui ninguém se importa com os teus amigos jornalistas nem os teus sessenta livros editados e traduzidos ao sueco" (tradução nossa). 
Esses são alguns exemplos para demonstrar que trabalhar com textos como os poemas-slam, "cujos temas atravessam tópicos emergentes como as sexualidades, os gêneros, as raças/etnias, as gordofobias, etc. pode ser uma possibilidade de travessia por caminhos outros em que seremos guiados pelos 'suleares' e não mais pelos norteares" (CADILHE; LEROY, 2020, p. 254) em nossa prática docente.

Pela análise do nosso corpus, principalmente após assistir às competições de poesia falada selecionadas, observase seu potencial interdisciplinar, mobilizando toda a comunidade escolar, e não apenas os docentes de línguas, como se poderia supor. O mais impactante é a quantidade de discentes motivados a escrever, declamar e ouvir poesias que suscitam debates sobre temas atuais e que os inquietam, o que nos permite afirmar que o Slam Interescolar tem sido um grande aliado no processo de formação cidadã nas instituições onde o evento ocorre. Como defendeu Neves (2021, p. 83),

[b]asta ler ou escutar alguns poemas-slams nos eventos de slams escolares para ficarmos logo impressionados com a qualidade dos textos dos estudantes-slammers, seja na criação de neologismos, no uso de anáforas, aliterações, onomatopeias, metáforas; seja na alternância de maiúsculas ou minúsculas para marcar o tom de voz.

Para que seja possível produzir esses campeonatos em escolas e atrelados ao ensino de espanhol, oferecemos, a seguir, orientações que podem auxiliar na concretização da proposta didática apresentada ao longo deste artigo.

\section{ETAPAS PARA A CRIAÇÃO DO SLAM ESCOLAR EM LÍNGUA ESPANHOLA}

A inclusão de um slam em língua estrangeira nas escolas brasileiras teria uma dinâmica bastante parecida com a que é feita em língua materna, sendo interessante partir das mesmas atividades básicas que as do Slam Interescolar SP. Antes de dar início ao projeto, a direção do colégio deve estar ciente dele, uma vez que será um evento que poderá mobilizar toda a instituição, incluirá dinâmicas que antes não faziam parte do planejamento e envolverá estudantes menores de idade que, para qualquer atividade fora do espaço escolar, precisarão obter a autorização dos respectivos responsáveis. Além disso, para não prejudicar o andamento das aulas e outras ações previstas para o ano letivo, é fundamental que tudo seja programado e informado a todos com antecedência, pois serão necessários vários encontros com diferentes turmas e com os demais interessados. Um ponto que cabe ressaltar sempre é que a participação no projeto não pode ser obrigatória, como tampouco se deve utilizá-lo como forma de avaliação.

Para que possamos executar a proposta, recomendamos as seguintes etapas:

1) Para formação do corpo docente e discente, bem como de todos os profissionais da instituição escolar interessados em participar, seriam oferecidas, ao menos, duas palestras: uma sobre a história e as características da corrente do poetry slam, abordando desde o período de sua criação, nos Estados Unidos, até sua chegada ao Brasil e a alguns países hispanofalantes; e outra para tratar especificamente do slam nas escolas, que já existe em diversos países, como França, Canadá, Alemanha, Burundi, Austrália e Estados Unidos (ASSUNÇÃO; JESUS, SANTOS, 2021). ${ }^{11}$ As exposições contariam com recursos audiovisuais, a partir do vasto material hoje disponível na rede, para que se tenha uma primeira ideia de como as competições acontecem. $\mathrm{O}$ ideal é que fossem realizadas por alguém que tenha bastante familiaridade com o tema, preferencialmente (se possível) por integrantes de alguma equipe de slam convidada, uma vez que seriam apresentadas as regras do evento (tempo de cada performance, exigência de três poemas autorais), seus distintos momentos (quantidade de rodadas e de participantes em cada uma) e as definições e funções dos sujeitos envolvidos (poeta competidor; público, do qual são escolhidos os jurados; slammasters, os apresentadores da disputa; e contador do tempo e das notas). Cabe ressaltar que essas normas podem ser discutidas e modificadas ao se criar o slam na escola, caso as pessoas envolvidas julguem necessário.

2) Em seguida, reservaríamos um dia para apresentações (ao vivo) de slam de poesia, produzidas pelo(s) coletivo(s) convidado(s). ${ }^{12}$ Vale a pena buscar informações sobre equipes que organizem competições na mesma cidade em que a escola se encontra e, caso não haja, pedir auxílio aos que já possuem experiência com o Interescolar,

11. Existem, ainda, registros de um Slam Poético Escuela, projeto organizado na Colômbia em 2019, e um Slam Poético Escolar, realizado em 2017 no Peru. Não os inserimos nesta lista porque não encontramos informações sobre sua regularidade ou novas edições.

12. Pela diversidade que caracteriza nosso país e cada grupo de poetry slam, seria bastante profícuo que mais de um coletivo pudesse fazer parte desta segunda etapa. Contudo, não seria uma logística simples, em especial, pelos custos das idas até cada escola, pois em alguns estados há poucos slams e em outros, ainda nem chegaram. 
como o próprio Slam da Guilhermina, cujo contato pode ser facilmente encontrado nas diversas redes sociais. O intuito é simular uma competição real, motivando os estudantes a participarem ativamente, inclusive na condição de jurados. Caso os funcionários responsáveis pelas escolas participantes considerem pertinente, e se for viável, dadas as especificidades das instituições e das turmas, encorajaríamos a ida a algum evento de slam, geral e/ou interescolar, antes de nos encaminharmos à próxima etapa. Isso contribuiria para o contato com todos os elementos que compõem esses campeonatos, dos quais ficam registrados somente um ângulo do que foram as performances e alguns momentos posteriores, como a reação do público e a atribuição das notas ao final, correndo o risco de parecer que tudo gira em torno de uma mera disputa. Certamente, isso só seria possível e aconselhável quando os slams retornarem ao modo presencial e não houver riscos para a saúde de ninguém, depois de superado o contexto de pandemia de Covid-19. Até que haja o controle dessa situação sanitária em nosso país, é importante acompanhar os campeonatos que têm sido promovidos de modo remoto e que já nos proporcionam uma boa noção do que é um slam.

3) A partir disso, seriam ministradas, pelos slammers a serem convidados e que estariam na função de poetasformadores, diferentes oficinas de poesia escrita e falada, com foco na performance. Esta fase do período formativo envolveria professores e estudantes e tem como objetivo introduzir a parte prática da criação de um poema-slam, servindo também para as escolas planejarem como o evento poderia ser organizado naquele contexto. Tendo em vista a realidade de muitas escolas brasileiras, cujas turmas costumam ter um número expressivo de alunos, a ideia é que essas oficinas sejam oferecidas para cada uma delas, em vez de reunir todos esses discentes em um mesmo dia e espaço.

4) Indo às salas de aula, começaria a ser inserido, aos poucos, o slam produzido em língua espanhola, utilizando vídeos, imagens e poemas-slam (que tenham sido publicados ou transcritos a partir desses vídeos) de campeonatos organizados por coletivos de diferentes países hispanófonos, tais como Argentina, México, Chile, Espanha, Uruguay e Colômbia, entre outros. Esses materiais - além dos textos citados de autores argentinos - podem ser encontrados em páginas oficiais de suas respectivas redes sociais e canais do YouTube. Neste penúltimo passo do projeto, caberia aos docentes mediar o processo de produção dos poemas pelos estudantes, lembrando que eles são livres para escolherem sua temática e forma, além de ser um texto pensado para ser oralizado posteriormente. Enfim, é o momento de estimulá-los a usar sua criatividade e lançar mão dos recursos linguísticos que, para eles, melhor expressem suas ideias, além de pôr em prática o que aprenderam nas oficinas.

5) Finalmente, teriam início o que chamamos anteriormente de Slam Escolar (ou Intraescolar), e que Alcalde definiu como "Slam Intersalas" (ALCALDE, 2021, p. 17), que se refere a esse período de preparação das instituições de ensino para o Interescolar. Uma vez ao mês, cada uma desenvolve seu próprio campeonato de poetry slam com estudantes do Ensino Fundamental e Médio até a batalha final, quando selecionam um(a) representante de cada nível para a disputa com as demais escolas participantes. É necessário definir previamente quem vai assumir as diferentes tarefas durante os campeonatos.

A concretização do Interescolar, que só ocorre quando duas ou mais instituições realizam o Intraescolar e se inscrevem para competir com as outras, poderia ser em um desses espaços escolares ou em algum centro cultural, como costuma acontecer com o de São Paulo. Isso vai depender da quantidade de instituições envolvidas, o que define o tamanho do público previsto e justifica a necessidade de um lugar maior ou menor. Os dias e horários da competição também vão variar segundo esses números, mas o ideal é que sejam divididos os estudantes de ensino fundamental para uma data e os de médio, para outra. Caso sejam poucos, bastaria separá-los em turnos ou horários de um mesmo dia. De qualquer forma, pela logística de um slam, observa-se que é preciso contar com a participação de muitos voluntários.

A partir dessa sugestão de etapas para a produção de um Slam Interescolar em espanhol, nota-se que suas diferenças em relação ao que ocorre em São Paulo consistiriam no idioma dos poemas e respectivas performances a serem estudadas e na etapa de seleção dos estudantes para o campeonato. Como a ideia é que esses textos estejam em língua espanhola, aqueles que pretenderem competir precisariam estar matriculados nesta disciplina. Nas instituições em que sua oferta é obrigatória, essa regra não faria sentido, mas nos casos em que é optativa, sim. A justificativa para a criação desse pré-requisito - que também explica, em certa medida, a inspiração para a proposta - é o fato de que essa área de ensino vem perdendo espaço no sistema educacional brasileiro. Isso se deve a distintos fatores, entre eles, decretos governamentais como a Lei Federal ${ }^{\circ}$ 13.415, de 2017, que altera a Lei de Diretrizes e Bases da Educação Nacional (LDB, $\mathrm{n}^{\circ}$ 9.394, de 1996) e revoga a Lei ${ }^{\circ}$ 11.161, de 2005, retirando a Língua Espanhola do 
currículo (SILVA JÚNIOR; ERES FERNÁNDEZ, 2019) e estabelecendo apenas o inglês como língua estrangeira obrigatória. Cabe lembrar que esta última ficou conhecida como a Lei do Espanbol, na qual se propôs que o ensino desse idioma fosse implantado na educação básica, sendo de oferta obrigatória no nível médio e facultativa no fundamental.

Diante dessa nova realidade a ser enfrentada, surge o movimento Fica Espanhol (ou \#FicaEspanhol), que ganhou força e passou a operar em diversas partes do país. Trata-se de uma corrente (iniciada no Rio Grande do Sul) constituída por ativistas político-linguísticos hoje distribuídos por todos os estados brasileiros e que estão interessados em garantir, por meio de ações como a proposição de políticas municipais e estaduais, a manutenção do ensino de língua espanhola na educação básica, respaldando-se, em especial, em documentos oficiais como a Constituição Federal de 1988 e a própria LDB.

A expectativa é de que, com a inserção de uma prática social que tem se mostrado tão impressionante no universo escolar, o espanhol consiga, ainda que a longo prazo, recuperar sua visibilidade e o reconhecimento de sua importância para a formação dos estudantes, superando a visão monolíngue que vem se impondo. Como se trata ainda de uma proposta, não há resultados (parciais ou finais), mas se espera que ela possa ser adaptada a diferentes instituições de ensino em que o espanhol seja ofertado, respeitando-se a autonomia de cada uma e suas respectivas realidades e necessidades.

\section{CONSIDERAÇÕES FINAIS}

Procuramos propor, neste trabalho, a criação de um Slam Interescolar produzido em espanhol como língua estrangeira em escolas brasileiras, inspirando-nos no êxito dessa modalidade de slam já existente no país (em língua portuguesa). Para justificar a relevância do projeto idealizado, iniciou-se o texto com uma revisão dos conceitos de letramento literário, letramento crítico e letramento de reexistência, relacionando-os às contribuições de uma LA indisciplinar e crítica para pensarmos uma prática docente suleada, intercultural e decolonial no ensino de línguas estrangeiras.

Uma forma de sintetizar um dos sentidos fundamentais de nossa proposta é a ideia de Rajagopalan (2005, p. 45) de que "o importante é não se esquecer que, em última análise, os nossos alunos precisam adquirir domínio da língua estrangeira para o seu próprio bem e para se tornarem mais aptos a enfrentar os novos desafios que o mundo coloca no seu caminho". Um desses desafios é que o estudante seja capaz de olhar para o outro, no encontro com culturas outras, como uma possibilidade a mais de ser e estar no mundo, e não em uma comparação que os inferiorize.

A escola não pode mais ser um lugar - como tantos outros - de reprodução das desigualdades sociais e das relações de poder, em que alguns indivíduos subjugam e silenciam os demais, como defendem Baptista (2019) e Souza (2011). Levar os slams de poesia para dentro das instituições escolares pode ser uma forma de combater essas práticas, fruto da colonialidade do poder e suas múltiplas dimensões.

\section{REFERÊNCIAS}

$2^{\circ}$ SLAM Interescolar SP - Isaac Quaresma - $1^{\circ}$ Lugar. (2016). 1 vídeo (3min 43s). Publicado pelo canal Slam da Guilhermina. [S. 1.: s. n.]. Disponível em: https://www.youtube.com/watch?v=BSUOFerCm3A\&feature=emb_logo. Acesso em: 22 jun. 2020.

ALCALDE, E. (2016). Slam na Educação: a poesia escrita com giz e dita com o coração. In: ASSUNÇÃO, C. et al. (orgs.). Slam da Guilhermina: três ponto zero. 1.ed. São Paulo: Slam da Guilhermina, p. 6-11.

ALCALDE, E. (2020). Podcast Podfalar: Episódio 2 - Poesia e Educação. Disponível em: https://ims.com.br/convida/acaoeducativa/emerson-alcalde/. Acesso em: 18 set. 2020.

ALCALDE, E. (2021). De Belleville ao Romano: o Slam da Guilhermina vai às escolas. In: ASSUNÇÃO, C. A.; JESUS, E. A.; SANTOS, U. S. (orgs.). Das ruas para as escolas, das escolas para as ruas: Slam Interescolar SP. São Paulo: LiteraRua, p. 14-17.

AMORIM, M. A. de; SILVA, T. C. da. (2019). O ensino de literaturas na BNCC: discursos e (re)existências possíveis. In: GERHARDT, A. F. L. M.; AMORIM, M. A. de (orgs.). A BNCC e o ensino de linguas e literaturas. 1ed. Campinas: Pontes, p. $153-179$. 
ASSUNÇÃO, C. A.; JESUS, E. A.; SANTOS, U. S. (orgs.). (2021). Das ruas para as escolas, das escolas para as ruas: Slam Interescolar SP. São Paulo: LiteraRua.

BALLESTRIN, L. (2013). América Latina e o giro decolonial. Revista Brasileira de Ciência Política, Brasília, n. 11, p. 89-117.

BAPTISTA, L. M. T. R. (2019). (De)Colonialidade da linguagem, lócus enunciativo e constituição identitária em Gloria Anzaldúa: uma "new mestiza". Polifonia, Cuiabá-MT, v. 26, n.44, p. 123-145.

BOHN, H. I. (2000). Os aspectos 'políticos' de uma política de ensino de línguas e literaturas estrangeiras. Linguagem \& Ensino, v. 3, n. 1 , p. 117-138.

BRASIL. (2018). Ministério da Educação. Base Nacional Comum Curricular. Brasília: MEC. Disponível em: http://basenacionalcomum. mec.gov.br/abase/. Acesso em: 26 nov. 2020.

CADILHE, A. J.; LEROY, H. R. (2020). Formação de professores de língua e decolonialidade: o estágio supervisionado como espaço de (re)existências. Calidoscópio, v. 18, n. 2, p. 250-270.

COSSON, R. (2009). Letramento literário: teoria e prática. 2.ed. São Paulo: Contexto.

DUBOC, A. P. (2014). Letramento crítico nas brechas da sala de aula de línguas estrangeiras. In: TAKAKI, N. H.; MACIEL, R. F. (orgs.). Letramentos em terra de Paulo Freire. Campinas: Pontes Editores, p. 195-207.

EDUCAÇÃO em Liberdade - Slam da Guilhermina e Slam Interescolar, com Emerson Alcalde. (2020). 1 vídeo (23min 49s). Publicado pelo canal Curadoria Hilst. [S. l.: s. n.]. Disponível em: https://www.youtube.com/ watch?v $=$ YLNEbW4rRfY\&feature=emb_logo. Acesso em: 28 nov. 2020.

ÉMERY-BRUNEAU, J.; YOBÉ, V. (2014). El slam en Quebec: de práctica social a objeto de enseñanza. Impossibilia - Revista Internacional de Estudios Literarios, Dimensiones de la literatura infantil y juvenil, Granada, n. 8, p. 247-268.

ESTRELA D’ALVA, R. (2011). Um microfone na mão e uma ideia na cabeça - o poetry slam entra em cena. Synergies Brésil, n 9 , p. 119-126.

EVELYN Giovana - campeã do Slam Interescolar 2018. (2020). 1 vídeo (2min 21s). Publicado pelo canal Slam da Guilhermina. [S. l.: s. n.]. Disponível em: https://www.youtube.com/watch?v=_7VLbBkYwcw. Acesso em: 28 nov. 2020.

FABRÍCIO, B. F. (2006). Lingüística Aplicada como espaço de "desaprendizagem": redescrições em curso. In: MOITA LOPES, L. P. (org.). Por uma Linguística Aplicada Indisciplinar. São Paulo: Parábola, p. 45-65.

FINNEGAN, R. (2005). The How of Literature. Oral Tradition, v. 20, n. 2, p. 164-187.

GROSFOGUEL, R. (2008). Para descolonizar os estudos de economia política e os estudos pós-coloniais: Transmodernidade, pensamento de fronteira e colonialidade global, Revista Crítica de Ciências Sociais, n. 80, p. 115-147.

KLEIMAN, A. (2013). Agenda de pesquisa e ação em Linguística Aplicada: problematizações. In: MOITA LOPES, L. P. (org.). Linguística Aplicada na Modernidade Recente - Festschrift para Antonieta Celani. São Paulo: Parábola, p. 39-58.

LA POESÍA en el cuerpo. (2012). Clarín, Buenos Aires, 15 de fevereiro de 2012. Revista N - Literatura. Disponível em: https:// www.clarin.com/literatura/slam-poesia-oralidad_0_H1wQbKP3PXe.html. Acesso em: 02 ago. 2019.

MARINS-COSTA, E. G. (2016). Letramento crítico: contribuições para a delimitação de um conceito. In: BAPTISTA, L. M. T. R. (org.). Autores e produtores de textos na contemporaneidade: multiletramentos, letramento crítico e ensino de línguas. 1 ed. Campinas: Pontes, p. 19-42.

MARINS-COSTA, E. G. (2020). Afinal, o que é letramento crítico? Palestra (live). Faculdade de Educação, Universidade Federal Fluminense. 
MATOS, D. C. V. S. (2018). O professor de espanhol como agente intercultural e as articulações necessárias na elaboração de materiais didáticos. In: MATOS, D.; PARAQUETT, M. (orgs.). Interculturalidade e identidades: formação de professores de espanhol. Salvador: Edufba, p. 17-34.

MATOS, D. C. V. S.; SILVA JÚNIOR, A. C. (2019). Linguística Aplicada e o SULear: práticas decoloniais na educação linguística em espanhol. Revista Interdisciplinar Sulear, Ano 2, No 2, p. 101-116.

MOITA LOPES, L. P. (org.). (2006). Por uma Linguística Aplicada Indisciplinar. São Paulo: Parábola.

NEVES, C. A. B. (2017). Slams - Letramentos literários de reexistência ao/no mundo contemporâneo. Linba D’Água (Online), São Paulo, v. 30, n. 2, p. 92-112.

NEVES, C. A. B. (2021). Letramentos literários em travessias na Linguística Aplicada: ensino transgressor e aprendizagem subjetiva da literatura. In: LIMA, E. Linguística aplicada na Unicamp: travessias e perspectivas. 1.ed. Bauru, SP: Canal 6 Editora, p. 65-88.

PARAQUETT, M. (2010). Multiculturalismo, interculturalismo e ensino/aprendizagem de espanhol para brasileiros. In: BARROS, C. S.; COSTA, E. G. M. (orgs.). Espanbol: ensino médio. (Coleção Explorando o Ensino; v. 16). Brasília: Ministério da Educação, Secretaria de Educação Básica, p.137-156.

PARAQUETT, M. (2011). La interculturalidad en el aprendizaje de español en Brasil. In: IV CONGRESO INTERNACIONAL DE FIAPE, 2011. Actas [...]. Madri: RedELE, p. 1-14.

PARAQUETT, M. (2012). A língua espanhola e a linguística aplicada no Brasil. Revista Abebache. São Paulo: ABH, v. 1, n. 2, p. $225-239$.

PHELAN, P. (2011). Ontología del performance: representación sin reproducción. In: TAYLOR, D.; FUENTES, M. (eds.). Estudios avanzados de performance. México: FCE, Instituto Hemisférico de Performance y Política, Tisch School of the Arts, New York University, p. 91-121.

QUIJANO, A. (2000). Colonialidad del poder, eurocentrismo y América Latina. In: LANDER, E. (comp.). La colonialidad del saber: eurocentrismo y ciencias sociales. Perspectivas latinoamericanas. Buenos Aires: CLACSO, p. 201-246.

RAJAGOPALAN, K. (2005). O grande desafio: aprender a dominar a língua inglesa sem ser dominado por ela. In: JORDÃO, C.; GIMENEZ, T; ANDREOTTI, V. (orgs.). Perspectivas educacionais e o ensino de inglês na escola pública. Pelotas: Educat, p. 37-48.

SCHMIDT, R. T. (2008). Centro e margens: notas sobre a historiografia literária. Estudos de Literatura Brasileira Contemporânea, $\mathrm{n}^{\circ} 32$. Brasília, p. 127-141.

SILVA JÚNIOR, A. F.; ERES FERNÁNDEZ, G. (2019). Ausência da língua espanhola na Base Nacional Comum Curricular: quais implicações esperar? In: GERHARDT, A. F. L. M.; AMORIM, M. A. de (orgs.). A BNCC e o ensino de línguas e literatura. 1ed. Campinas: Pontes, p. 181-208.

SOUZA, A. L. S. (2011). Letramentos de reexistência: poesia, grafite, música, dança: hip-hop. São Paulo: Parábola.

STREET, B. V. (2014). Letramentos sociais: abordagens críticas do letramento no desenvolvimento, na etnografia e na educação Tradução: Marcos Bagno. São Paulo: Parábola.

WALSH, C. (2009). Interculturalidad, Estado y Sociedad: luchas (de)coloniales de nuestra época. Quito, Universidad Andina Simón Bolívar: Editorial Abya-Yala.

WALSH, C. (2013). Introducción - Lo pedagógico y lo decolonial: entretejiendo caminos. In: C. WALSH (ed.). Pedagogías decoloniales: prácticas insurgentes de resistir, (re)existir y (re)vivir. Tomo I. Quito-Ecuador: Ediciones Abya-Yala, p. 23-68.

ZEA, L. (2005). Discurso desde a marginalização e a barbárie; seguido de A filosofia latino-americana como filosofia pura e simplesmente. Tradução: Luis Gonzalo Acosta Espejo et al. Rio de Janeiro: Garamond. 
ZUMTHOR, P. (2014). Performance, recepção, leitura. Tradução: Jerusa Pires Ferreira e Suely Fenerich. $1^{\text {a }}$ ed. São Paulo: Cosac Naify.

Recebido: 5/7/2021

Aceito: 28/9/2021

Publicado: 13/10/2021 